\title{
The alignment of the glass elements from radiation-resistant optical glass K-208 for thermal control coatings of spacecraft
}

\author{
P.A. Vyatlev ${ }^{1}$, D.V. Sergeev ${ }^{1, \dagger}$, V.N. Sigaev ${ }^{2}$, V.K. Sysoyev ${ }^{1}$, A.V. Shulepov ${ }^{3}$ \\ ${ }^{\dagger}$ sdv@laspace.ru \\ ${ }^{1}$ Federal State Unitary Enterprise NGO of S.A.Lavochkin, 24 Leningradskaya St., Khimki, Russia \\ ${ }^{2}$ RHTU of D.I.Mendeleev, 9 Miusskaya sq., Moscow, Russia \\ ${ }^{3} \mathrm{MGTU}$ «STANKIN», 3aVadkovsky per., Moscow, Russia
}

\begin{abstract}
Optical coatings, i.e. elements of temperature controlling coatings, based on ultrathin elements of optical radiation-resistant glass K-208 with thickness of about $150 \mu \mathrm{m}$, are successfully used as passive means of temperature controlling tools in space engineering. The paper considers the process of fabrication of glass elements for temperature controlling coatings, which includes the following stages: drawing of glass ribbon from a brick of glass heated to a temperature of high plastic consistency through a steel draw-hole; dimensional cutting of the glass ribbon that is done by means of a diamond scriber; process of thermal plastic flattening of glass elements done in a furnace by heating to a temperature of plastic consistency under load. The process of drawing from a highly plastic brick of large sizes leads to difficulties in providing the flatness of the ribbon drawn. The glass ribbon has a convex shape. In order to achieve a required deviation from the flatness, the technique of warm plastic deformation of the glass elements under load is used. The process of flattening of convex glass elements is considered, temperature regimes and holding time, which allow one to achieve minimum deviations from the flatness (below $10 \mu \mathrm{m}$ ) are chosen. Measurements of flatness deviations of glass elements before and after flattening are carried out by a profile recorder 252 "Caliber". The results of the measurements prove the efficiency of the flattening technique chosen. The flattening process makes it possible to fabricate thin elements of K-208 glass with minimum flatness deviations that allows for their application in the units of temperature controlling coatings in the temperature controlling systems of space vehicles.
\end{abstract}

Keywords: glass elements, flattening.

\section{Выравнивание стеклянных элементов из оптического радиационно-стойкого стекла К-208 для терморегулирующих покрытий космических аппаратов}

\author{
Вятлев П.А. ${ }^{1}$, Сергеев Д.В. ${ }^{1, \dagger}$, Сигаев В.Н. ${ }^{2}$, Сысоев В.К. ${ }^{1}$, Шулепов А.В. ${ }^{3}$ \\ ${ }^{\dagger}$ sdv@laspace.ru
}

${ }^{1}$ ФГУП «НПО им. С.А.Лавочкина», ул. Ленинградская 24, Химки, Россия ${ }^{2}$ ФГБОУ ВО «РХТУ имени Д.И. Менделеева», Миусская площадь 9, Москва, Россия ${ }^{3}$ ФГБОУ ВО «МГТУ «СТАНКИН», Вадковский переулок 3а, 127055, Москва, Россия

В настоящее время в космической технике в качестве пассивных средств для систем обеспечения теплового режима успешно применяются оптические покрытия (элементы терморегулирующих покрытий) на основе ультратонких (толщиной порядка 150 мкм) элементов из оптического радиационно-стойкого стекла К-208. В статье рассматривается процесс изготовления стеклянных элементов для терморегулирующих покрытий, включающий в себя следующие стадии: - вытягивание стеклоленты из блока нагретого до температуры высоко пластичного состояния стекла через стальную фильеру; - размерную резку стеклоленты, осуществляемую при помощи скрайбирующего алмазного инструмента; - процесс теплового пластического выравнивания стеклянных элементов, осуществляемый в печи при нагреве до температуры пластичности стекла под нагрузкой. Процесс вытяжки из высоко пластичного блока большой размерности приводит к возникновению трудностей по обеспечению плоскостности вытягиваемой стеклоленты. Форма стеклоленты имеет выпуклую форму. Для обеспечения требуемого отклонения от плоскостности 
применяется технология тепловой пластической деформации под нагрузкой стеклянных элементов. Рассмотрен процесс выравнивания выпуклых стеклянных элементов, выбраны температурные режимы и время выдержки, позволяющие получать минимальное отклонение от плоскостности (до 10 мкм). Проведены измерения отклонения от плоскостности стеклянных элементов до и после процесса выравнивания при помощи профилометра-профилографа 252 «Калибр». Результаты проведенных измерений подтверждают эффективность выбранной технологии выравнивания. Процесс выравнивания дает возможность получать тонкие элементы из стекла К-208 с минимальным отклонением от плоскостности, что позволяет применять их в элементах терморегулирующих покрытий систем терморегулирования космических аппаратов

Ключевые слова: стеклянные элементы, выравнивание.

\section{1. Введение}

Ультратонкие стеклянные элементы с толщиной $\sim 150$ мкм и размерами от $20 \times 10$ до $80 \times 4$ мм из радиационно-стойкого стекла марки К208 применяются для решения следующих задач при эксплуатации космических аппаратов (КА) [1,2]:

- защитные покрытия фотоэлементов солнечных батарей;

- термооптические покрытия радиаторов-теплообменников системы терморегулирования.

К стеклянным элементам предъявляются высокие требования по геометрическим параметрам:

- размерам - толщине, длине, ширине;

- качеству поверхности - светорассеиванию и отсутствию каверн;

- отклонению от плоскостности.

Технология изготовления стеклянных элементов основана на нагреве полированных стеклянных блоков из стекла К208 размером 400×400×400 мм до высоко вязкого состояния с последующей вытяжкой стеклоленты толщиной около 150 мкм и шириной около 60 мм через фильеру из нержавеющей стали [3].

Качество полировки фильеры определяет качество поверхности стеклоленты. Данный способ изготовления позволяет получать ленту из стекла марки К-208 с толщиной от 80 до 200 мкм. Стеклолента толщиной 150-170 мкм получаются вытягиванием стекломассы при температуре $920-940^{\circ} \mathrm{C}$ через фильеру с шириной щели 4,5 мм со скоростью вытяжки 23-28 мм/с в зависимости от температуры печи. Увеличение скорости вытяжки до 38 мм/с позволяет вытягивать стеклоленту толщиной 80 мкм.

После вытяжки происходит отжиг стеклоленты в электрической камерной печи для снятия внутренних напряжений в стекле, возникающих при остывании после вытяжки.

Размерная резка стеклоленты и получение заготовок требуемого размера осуществляется при помощи алмазного инструмента для скрайбирования.

Процесс вытяжки из высоко пластичного блока большой размерности приводит возникновению трудностей по обеспечению плоскостности вытягиваемой стеклоленты. Как правило, форма стеклоленты имеет вид, показанный на рис. 1 и характеризуется тремя областями: облоями - утолщениями по обоим краям, которые при резке удаляются и областью основного материала, выпуклого в одном из направлений.

\section{2. Выравнивание стеклянных элементов}

Для обеспечения требуемого отклонения от плоскостности применяется технология тепловой пластической деформации под нагрузкой стеклянных элементов. Для этого в стальную оправу (рис. 2) укладывается стопка стеклянных элементов толщиной 160 мкм из стекла марки К-208 с прокладкой каждого элемента кварцевыми шлифованными пластинами. На стопку устанавливается калиброванный груз весом около 480 г.

Оправа с двумя стопками стекол помещается в печь с регулируемым режимом температуры, в которой происходит нагревание до температуры, при которой происходит размягчение и выравнивание стеклянных элементов.

В результате проводимых экспериментов в рамках «температура-время-усилие нагрузки» установлено, что минимальное отклонение от плоскостности элементов получено при нагрузке 480 г и временной циклограмме температуры, представленной на рис. 3.

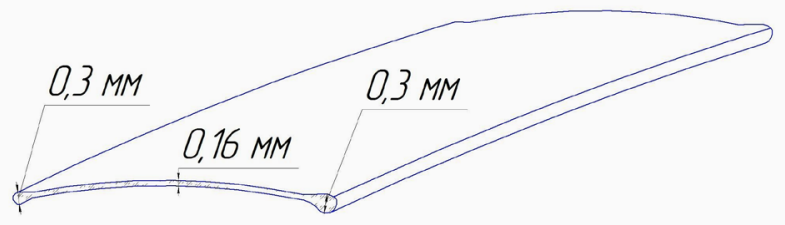

Рис. 1. Заготовка стеклоленты из оптического стекла марки K-208.

Fig. 1. Preparation of glass tape made of optical glass brand K-208.

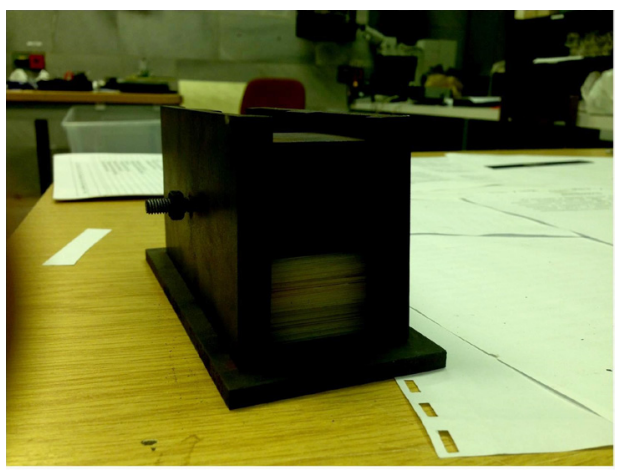

Рис. 2. Стопка стеклянных и кварцевых пластин (по схеме «сэндвич») в оправе с грузом.

Fig. 2. Stack glass and quartz plates ("sandwich") in frame with the load. 


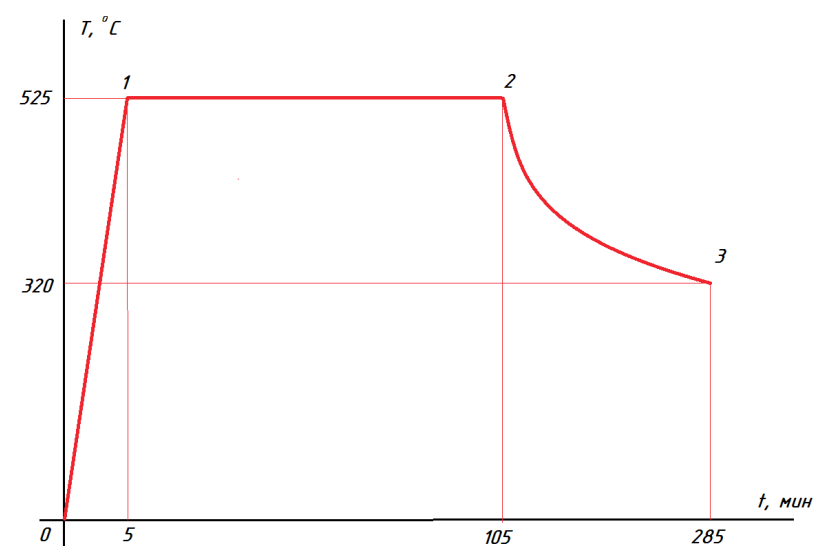

Рис. 3 Температурная циклограмма печи при выравнивании стеклянных элементов.

Fig. 3 Temperature sequence diagram of the furnace in alignment of the glass elements.

Пластина из оптического стекла К208 (не выровненная) The plate of the optical glass K208 (not aligned)

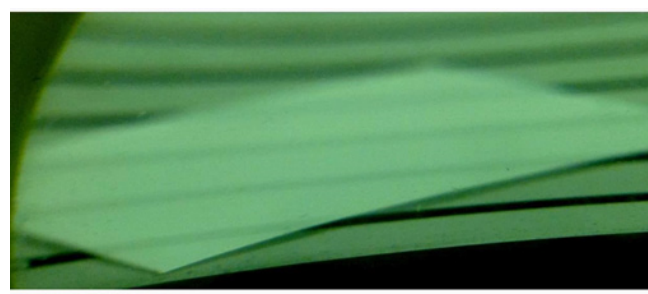

$0,2-0,3 \mathrm{MM}$

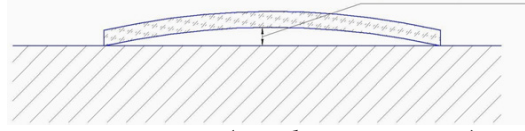

Стекло №1 (профиль поперек)

The glass No. 1 (the profile across)

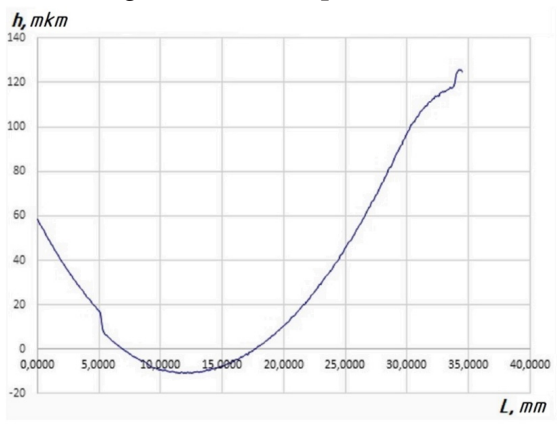

Стекло №1 (профиль вдоль)

The glass No. 1 (the profile along)

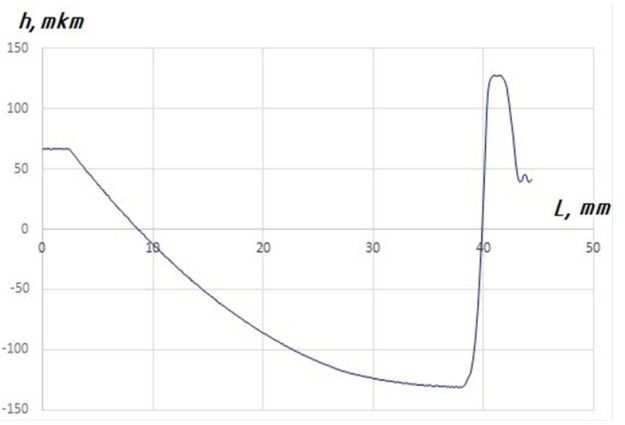

(a) Не выровненные стекла / Not aligned glass
При выборе температуры выравнивания стеклянных элементов было обнаружено, что при повышении температуры выше $530^{\circ} \mathrm{C}$ на поверхности элементов появляются каверны, количество которых превышает допустимый уровень. Механизм возникновения каверн авторы связывают с наличием газовых включений на границе кварцевая подложка - стеклянный элемент.

Для определения качественных характеристик процесса выравнивания произведены сравнительные измерения отклонения от плоскостности стеклянных элементов до и после выравнивания. Измерения производились при помощи профилометра-профилографа 252 «Калибр» с индуктивным датчиком. Щуп представляет собой алмазную иглу радиусом 10 мкм, измерительное усилие составляет $0,02 \mathrm{H}$.

Измерения производились в двух ортогональных направлениях посередине образцов. Проведенные измерения формы поверхности стеклянных элементов до и после выравнивания представлены на рис. 4.

Пластина из оптического стекла К208 (выровненная) The plate of the optical glass K208 (aligned)

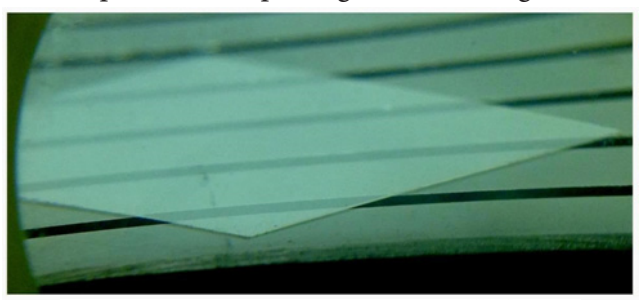

$<0,1 \mathrm{MM}$

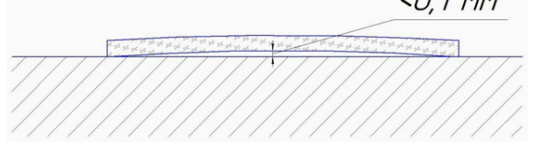

Стекло №2 (профиль поперек)

The glass No. 2 (the profile across)

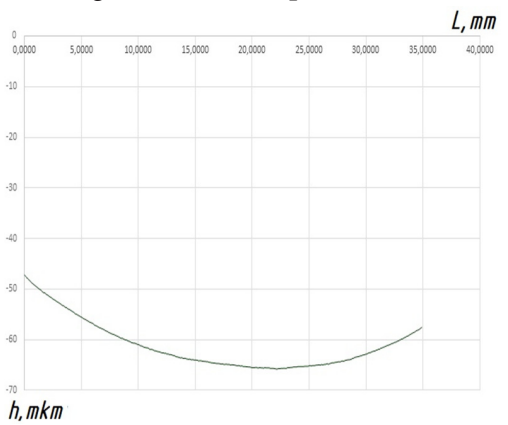

Стекло №2 (профиль вдоль)

The glass No. 2 (the profile along)

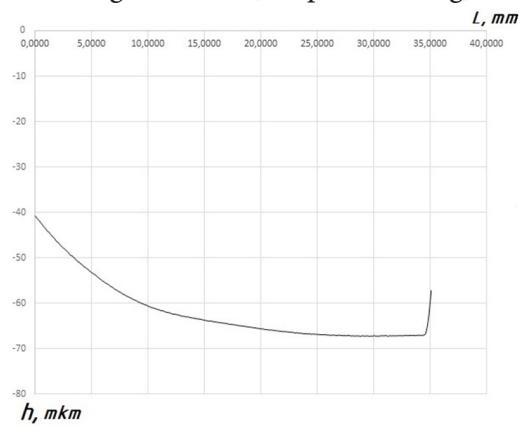

(b) Выровненные стекла / Aligned glass

Рис. 4. Измерения профиля стекол (Станкин) до (а) и после (b) выравнивания.

Fig. 4. Profile measurement of glass (Stankin) before (a) and after (b) alignment. 
Были проведены долговременные исследования изменения формы выровненных стеклянных элементов, которые позволили установить, что температурный режим выравнивания и его длительность снимают все температурные напряжения тонких стеклянных элементов, что не приводит к изменению их формы.

\section{3. Заключение}

Полученные результаты подтверждают эффективность выбранной технологии выравнивания тонких стеклянных элементов.

Процесс выравнивания позволяет получить тонкие элементы из стекла К-208 с минимальным отклонением от плоскостности, что позволяет их применять в элементах терморегулирующих покрытий систем терморегулирования космических аппаратов.

\section{Литература/References}

1. Летин, В.А. Защитные покрытия солнечных батарей космических аппаратов с большим ресурсом/В.А. Летин, Л.С. Гаценко, Т.А. Агеева, В.Ф. Суркова // Автономная энергетика: технический прогресс и экономика, 2008 - 2009. № 24-25. С. $3-13$.

2. Price M/Solar Cell Coverglasses for Satellites in the Intermediate Earth Orbit/M/Price, C. Kitchin, H. Eaves, R. Crabb, P. Buia - 5th European Space Power Conference Proceedings, Tarragona, Spain: 21-25 September, 1988.

3. В.К. Сысоев Технология получения тонких защитных покрытий солнечных батарей для космической техники/В.К. Сысоев [и др.] // Успехи в химии и химической технологии. - Т.25. —№ 5-2011. 